\title{
Two models for the climate change related development of sea levels in the North Sea - a comparison
}

\author{
F. Kauker*, H. Langenberg \\ G KSS Research C entre, M ax-Planck Str., 21502 G eesthacht, G ermany
}

\begin{abstract}
Two models of the North Sea are compared with respect to their performance in the assessment of sea level changes in a changing climate: the OPYC model, originally designed as a global ocean model and run in a regional version, and the HAMSOM, which was built as a shelf sea model and applied to an extended region in a simplified version. Both models agree very well in their hindcast skill as measured by correlation and explained variance. The reaction of both models to the ' $2 \times \mathrm{CO}_{2}$ ' and 'control' runs of the time slice experiments of the DKRZ (German Climate Computing Center) is also very similar and indicates an increase of up to $30 \mathrm{~cm}$ of winter mean sea levels and no significant (compared with the variability in the past) impact on the intra-monthly $90 \%$ quantiles. It is concluded that sea level is a rather robust parameter that could still be assessed with some confidence if both models were simplified further.
\end{abstract}

KEY WORDS: N orth Sea $\cdot$ Sea level $\cdot$ Hindcast $\cdot 2 \mathrm{CO}_{2} \cdot$ Storm surge

\section{INTRODUCTION}

Considerable interest is focussed on the evaluation and regionalisation of GCM climate change scenarios for various parameters such as temperatures (see e.g. Machenhauer et al. 1999), storminess (Beersma et al. 1997), wave heights (Günther et al. 1998) and sea levels/storm surges (Flather \& Smith 1998, Langenberg et al. 1999). For the restricted impact in a regional setting, it is also of interest to determine the minimum requirements in order for a model to faithfully reproduce the feature that is investigated.

For the case of sea levels, in the past and their development in a ' $2 \times \mathrm{CO}_{2}$ ' climate change scenario, the determination of the above-mentioned requirements is addressed here by comparison of two rather different primitive equation-based numerical circulation models. A regional version of the OPYC (Ocean isoPYCnal

*Present address: Alfred Wegener Institute for Polar and Marine Research, Columbusstraße, 27568 Bremerhaven, Germany. E-mail: fkauker@awi-bremerhaven.de model; Kauker \& Oberhuber 1998), a 3-D baroclinic model that was originally designed for global ocean applications (see e.g. Oberhuber 1993), is applied to the North Sea and the adjacent ocean areas. Its results are compared to a version of HAMSOM (HAMburg Shelf Ocean Model), which was originally developed as a 3-D baroclinic shelf sea model (see e.g. Langenberg 1998). For the present application, it was reduced to a 2-D version with a prescribed 'frozen' density structure from climatological monthly mean distributions for this regional evaluation with respect to sea level variations (Langenberg et al. 1999).

Additional to various differences between the numerical representations of the 2 models, such as the horizontal and vertical discretization, the tides are taken into account in different ways: In the OPYC model the tides are calculated separately in a barotropic tide model and only the bottom stress and tidal residual currents are added to the 3-D OPYC model, which has a time step of $3 \mathrm{~h}$. In HAMSOM the tides are calculated explicitly with a time step of $10 \mathrm{~min}$. 
Here, the evaluation performed by Langenberg et al . (1999) is repeated with the results of the OPYC model for $15 \mathrm{yr}$ (1979 to 1993) and for the high resolution time slice experiment of the ' $2 \times \mathrm{CO}_{2}$ ' scenario of the German Climate Computing Centre (Bengtsson et al. 1995, Cubasch et al. 1995). The results of the 2 different models are compared and differences are evaluated with respect to the relevance of different processes for an accurate assessment of sea level variations.

In the OPYC model, as well as the ' $2 \times \mathrm{CO}_{2}$ ' scenario experiment, a scenario experiment was performed where, additional to the changed meteorological forcing, the changes of the temperature and salinity and the related change in the sea level due to the thermal expansion were added at the lateral boundaries. From this experiment the potential effect of thermal expansion on the variability of sea levels along the North Sea coast can be estimated.

\section{THE MODELS}

\subsection{OPYC}

The regional OPYC model (Kauker \& Oberhuber 1997, Kauker 1998) was developed to estimate sea level changes and changes in the temperature and salinity in a different climate for the North Sea. Also the influence of a different state of the adjacent oceans was to be studied. Therefore, the North Sea and the adjacent Northeast Atlantic as well as the GreenlandIceland-Norwegian Seas (GIN Seas) are modeled. The model area is rotated and approximately given by the following 4 corners: $37^{\circ} 4^{\prime} \mathrm{N}, 3^{\circ} 49^{\prime} \mathrm{W}, 44^{\circ} 44^{\prime} \mathrm{N}$, $29^{\circ} 0^{\prime} \mathrm{E}, 61^{\circ} 49^{\prime} \mathrm{N}, 29^{\circ} 11^{\prime} \mathrm{W}$, and $80^{\circ} 13^{\prime} \mathrm{N}, 25^{\circ} 44^{\prime} \mathrm{W}$. The horizontal resolution varies from $1 / 2^{\circ} \times 1 / 2^{\circ}$ at the lateral boundaries to $6^{\prime} \times 6^{\prime}$ in the central North Sea. The top-most layer is formulated as a mixed layer. The deeper ocean is discretized in the vertical with 14 Lagrangian isopycnal layers. The 3-D OPYC model solves the primitive equation with a time step of $3 \mathrm{~h}$, i.e. it solves the slow barotropic and baroclinic modes. A barotropic tide model, which solves the faster tidal modes, is coupled to the 3-D model. The 4 strongest partial tides are prescribed at the lateral boundaries of the tide model. The 3-D model is coupled to the tide model via the bottom stress and the residual circulation of the tide model.

The density varies according to advection of temperature and salinity as well as surface fluxes. An annual mean flux adjustment for heat and freshwater is applied in the Northeast Atlantic and the GIN Seas, but not in the North Sea. Therefore, the flux adjustment stabilizes the lateral boundary conditions of the
North Sea and has no direct influence on the North Sea. The freshwater input from the rivers is calculated with the help of a soil model and a discharge model. For example, the simulated freshwater input of the Elbe in the hindcast $\left(840 \mathrm{~m}^{3} \mathrm{~s}^{-1}\right)$ compares well with the observation $\left(710 \mathrm{~m}^{3} \mathrm{~s}^{-1}\right)$ (Kauker 1999).

In the hindcast, the surface fluxes are taken from the ECMWF reanalysis (Gibson et al. 1997) from 1979 to 1993. In both the hindcast and the time slice experiments the momentum equation is forced by wind stress as given by the ECM WF reanalysis and the time slice experiments. The forcing data are available every $12 \mathrm{~h}$.

The OPYC data show no (or only small) intra-daily variability because of the 3 hourly time step of the model, the explicit modelling of the tides, and the 12 hourly forcing data. Therefore, the OPYC data used in this analysis are daily values at 12:00 $\mathrm{h}$. Unlike for the HAMSOM model (see Section 2.2), no corrections are applied.

\subsection{HAM SOM}

The version of HAMSOM used in this application goes back to the model introduced by Backhaus (1985). The version used here has been described in more detail in Langenberg et al. (1999) and will thus be introduced only briefly. It is a 2-D primitive equation model for the North-West-European Shelf, covering the area from $47^{\circ} 35^{\prime} \mathrm{N}$ to $65^{\circ} 47^{\prime} \mathrm{N}$ and from $15^{\circ} 5^{\prime} \mathrm{W}$ to $30^{\circ} 5^{\prime} \mathrm{E}$, with a grid size of $6^{\prime}$ in the meridional direction and $10^{\prime}$ in the zonal direction. A time step of $10 \mathrm{~min}$ is used and 8 partial tides are prescribed at the open boundaries. The climatological monthly mean baroclinic pressure gradient is calculated from 3-D temperature and salinity charts combined from Damm (1989) and Tomczak \& Goedecke (1962), then averaged over the water column and inserted in the model. This procedure does not account for any year-to-year changes in the density structure, but gives more realistic surface elevation distributions than a purely barotropic treatment.

Wind stress and atmospheric pressure are prescribed at the sea surface. For the hindcast, mean sea level pressures from the DNMI (Det Norske M eteorologisk Institutt) are used and for the years 1984 to 1992 complemented with ECMWF analyses where no DNMI data were available. Wind stress is calculated following an approach by Luthardt \& Hasse (1983). For both the GCM scenario and control run, wind and pressure data were available and wind stress was obtained according to Smith \& Banke (1975). To assess the influence of the different schemes for the calculation of wind stress, a sensitivity run with high wind speeds was run for $1 \mathrm{mo}$, using the different schemes. At the 
Cuxhaven tide gauge, the difference was less than $1 \mathrm{~cm}$ at peak high water level. This was considered to be negligible, especially as in the following discussion $90 \%$ quantiles are used rather than peak levels, and the differences in wind stress obtained from the 2 approaches decrease quickly with decreasing winds.

To investigate the sensitivity of simulated storm surge heights to 2-D versus 3-D simulation, the model was run in a 3-D configuration for 1 mo. For this test, we chose February 1962, which comprised 2 large storm surges in the German Bight, on 12/13 February and 16/17 February, to obtain results for high-wind conditions. In these test runs, peak water levels were on the order of $10 \mathrm{~cm}$ higher (for the 5 high tide water levels within the 2 sets of storm surges) when the 3-D configuration was used. However, the increase in peak water level was broadly proportional to absolute water height, and it was thus concluded that an implementation of model output statistics would yield satisfactory results, while saving computational costs. Additionally, tide gauges that are positioned right at the coast (whereas model results represent a square of $10 \times$ $10 \mathrm{~km}$ ) should not be expected to produce the same peak water levels. Thus, where observations are available, the high tide water levels of the HAMSOM results are subjected to empirical model output statistics: a linear/quadratic function (linear in the low range, with a quadratic increase towards higher water levels) was found to deliver the best results. For each tide gauge, such a function is fitted empirically to obtain an estimate for the observed high tide water levels from the simulated levels at the nearest grid point. The function is then used to correct all the simulated values. For the evaluation of the time slice experiment, the correction is not applied in order to assess all the points along the North Sea coastline and not only the ones where observations are available. As the correction procedure is applied neither to the assessment of past variability nor to the time slice experiment results, both values are underestimated in the same way. The empirical correction is a 1-to-1 function. Therefore, a change that might occur in high tide water levels (in potential future observations) due to a changing climate would translate into a change in the simulated values, by inversion of this function, and would thus be detected by a comparison of uncorrected values in the past and in the scenarios.

\section{RESULTS}

Following the analysis by Langenberg et al. (1999), the results of both models are presented for 2 entities: first, the winter mean sea levels (where winter is taken to encompass the months November to March), and second, the anomalous intra-monthly $90 \%$ quantiles (i.e. the differences of quantiles and winter means) for the same months. In this way it is possible to distinguish whether the whole distribution of sea levels is shifted in height or if the extremes become more extreme while the mean value remains the same. Langenberg et al. (1999) have shown that the former effect is much stronger for doubled atmospheric carbon dioxide concentrations as well as for the trends in the past $40 \mathrm{yr}$. However, thermal expansion was not investigated there. As the design of the regional OPY C model allows such an analysis, this question will be addressed here (see Section 3.3).

Observed sea levels along the continental coast are used to compare with the model results. The available observational data differ slightly between different tide gauges. The Dutch, German and Danish tide gauges record high and low tide water levels, respectively. Here the analysis is based on the high tide water level (approx. 2 values $\mathrm{d}^{-1}$ ), i.e. about 60 values $\mathrm{mo}^{-1}$ are used. At Smogen, tidal excursion is very low due to an amphidromic region, and therefore only daily mean values are available.

\subsection{Hindcast}

Time series of winter mean sea levels and monthly $90 \%$ quantiles from the 2 models and observations, respectively, are shown in Fig. 1 . Clearly, the uncorrected HAM SOM produces less variability than OPYC, in the winter mean as well as in the quantiles. Sensitivity experiments indicate that the reduced variability may be due to the 2-D formulation of HAMSOM that is used in this application. Another possible source of lower variability in HAM SOM is the difference in the wind fields (wind stress from a 3-D model [OPYC] vs wind stress inferred from atmospheric surface pressures [HAMSOM]). After the correction is applied, both models have a similar skill in the reproduction of observations (see Table 1), measured in correlation for all gauge stations except Hoek van Holland, where OPYC has lower correlations. A comparison of the explained variances shows that the (uncorrected) OPYC model describes less variance than the (corrected) HAMSOM model.

The similarity of the results of the 2 models indicates that the differences in model formulation do not decisively influence the sea levels that are calculated. Apparently, storm surge situations that determine the $90 \%$ quantiles of a month in general extend over at least $1 \mathrm{~d}$, so that it does not make much difference whether daily values at 12:00 $\mathrm{h}$ or all high water levels are regarded. Also, the tidal formulation from the OPYC seems sufficient to achieve reasonable results. 
Finally, the 2-D formulation of HAMSOM with frozen temperature and salinity fields accounts for as much sea level variation (just with a smaller amplitude) as the more refined OPYC.

\subsection{Scenario}

The regionalisation of the time slice scenario gives similar results as the hindcast. Fig. 2 shows the changes in winter mean sea levels due to doubled atmospheric carbon dioxide concentrations for coastal stations around the North Sea as simulated by the 2 models, along with an account of the variability in the past (shaded bands). Like in the hindcast, the variability is higher in the OPYC results (HAM SOM results are shown without correction), but the pattern is consistent in both models: the expected changes in mean sea levels in a ' $2 \times \mathrm{CO}_{2}$ ' scenario amount to about $2 \mathrm{SD}$ of the $5 \mathrm{yr}$ moving averages in the hindcast.

The same analysis for the monthly $90 \%$ quantiles is shown in Fig. 3. Again, both models show good agreement in the pattern, but the variability in OPYC is larger. This result confirms the findings of Langenberg et al. (1999), that the main effect to be expected from increased atmospheric carbon dioxide concentrations (according to the time slice experiments) is an increase in mean sea levels rather than extremes.

Table 1. Skill of OPYC and HAMSOM in reproducing observed intra-monthly 50 and $90 \%$ percentiles

\begin{tabular}{|c|c|c|c|c|c|c|c|c|}
\hline \multirow[t]{3}{*}{ Quantile } & \multicolumn{4}{|c|}{ Correlation } & \multicolumn{4}{|c|}{ Explained variance } \\
\hline & \multicolumn{2}{|c|}{ OPYC } & \multicolumn{2}{|c|}{ HAMSOM } & \multicolumn{2}{|c|}{ OPYC } & \multicolumn{2}{|c|}{ HAMSOM } \\
\hline & $50 \%$ & $90 \%$ & $50 \%$ & $90 \%$ & $50 \%$ & $90 \%$ & $50 \%$ & $90 \%$ \\
\hline Vlissingen & 0.72 & 0.75 & 0.65 & 0.74 & 42 & 48 & 35 & 23 \\
\hline Hoek van Holland & 0.64 & 0.73 & 0.84 & 0.87 & 28 & 46 & 66 & 74 \\
\hline Den Helder & 0.73 & 0.80 & 0.74 & 0.76 & 36 & 51 & 54 & 53 \\
\hline Harlingen & 0.76 & 0.82 & 0.85 & 0.82 & 27 & 53 & 67 & 63 \\
\hline Delzijl & 0.81 & 0.81 & 0.85 & 0.83 & 52 & 52 & 70 & 66 \\
\hline Cuxhaven & 0.80 & 0.83 & 0.88 & 0.87 & 38 & 56 & 74 & 74 \\
\hline Esbjerg & 0.79 & 0.88 & 0.79 & 0.79 & 23 & 70 & 62 & 58 \\
\hline
\end{tabular}
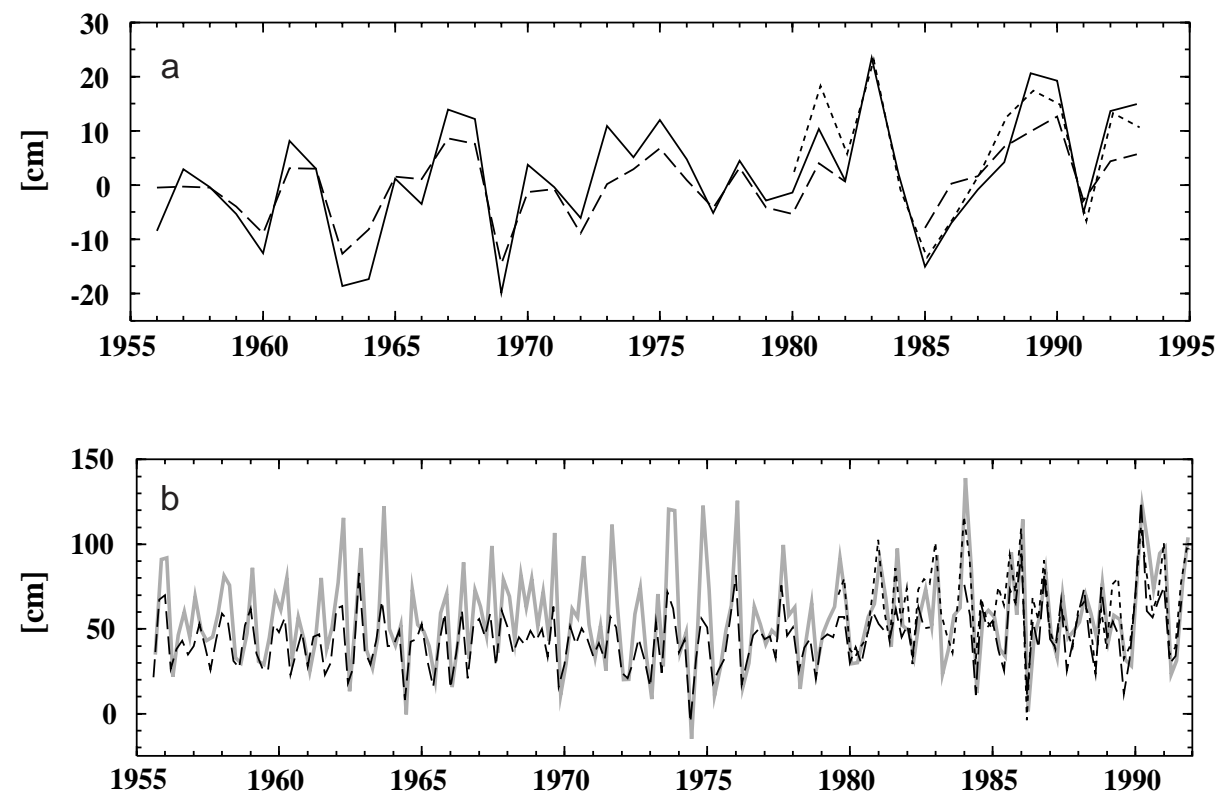

Fig. 1. (a) Time series of the anomalous winter mean (NDJ FM) sea level in Cuxhaven for the winters 1955/56 to 1992/93. Observation (--), OPYC (----); only the winters 1979/80 to 1992/93), and HAMSOM (- - - ). (b) Time series of the $90 \%$ percentiles of intra-monthly storm-related sea level variations in Cuxhaven. Observation (_-), OPYC (----); only the winters 1979/80 to 1992/93), and HAM SOM (- - -) 


\subsection{Thermal expansion experiment}

With the OPYC model, an experiment regarding the effect of thermal expansion of the ocean, additional to the increase of atmospheric carbon dioxide concentrations, on mean sea levels as well as the height of extremes was carried out. Of the 2 models that are presented in this paper, the OPYC has been shown to simulate the variability in the past more realistically, making it more suitable for such an experiment. The question is whether or not there are nonlinear interactions of a non-negligible magnitude between sea level and wind stress that work towards a broadening of the distribution of surges. If this was the case, we would not only expect an increase in the mean sea level, roughly on the order of the thermal expansion effect, but an additional increase in the difference between extremes (represented by the $90 \%$ quantiles), and the winter means ought to be found.

In Figs. $2 \& 3$, for the OPYC model, the same analysis as before is shown for the case of a thermal expansion of the Atlantic Ocean by about $10 \mathrm{~cm}$, assumed to be realistic for the time of doubled atmospheric carbon dioxide concentrations (Cubasch et al. 1995). While there is an increase in the winter mean values, roughly by the same amount that the sea level was raised at the open boundaries (i.e. $10 \mathrm{~cm}$ ), the deviations between mean and extremes (Fig. 3) are negligible for most coastal points. More specifically, the ' $2 \times \mathrm{CO}_{2}+$ thermal expansion' run lies within the range of past variations as defined before, just the same as the ' $2 \times$ $\mathrm{CO}_{2}^{\prime}$ simulation. It is thus not to be expected that storm surge heights will increase faster than sea levels, in general, in the North Sea.

\section{DISCUSSION AND CONCLUSIONS}

The skill in the prediction of sea levels as assessed from the past is very similar in the 2 models. It does not seem likely that the drawbacks of the 2-D and not fully baroclinic formulation of the presently used version of HAMSOM cancel out with the possible difficulties associated with the external calculation of the tides. We conclude from the good agreement of the 2 models that sea levels are not essentially dependent on either feature of the model.
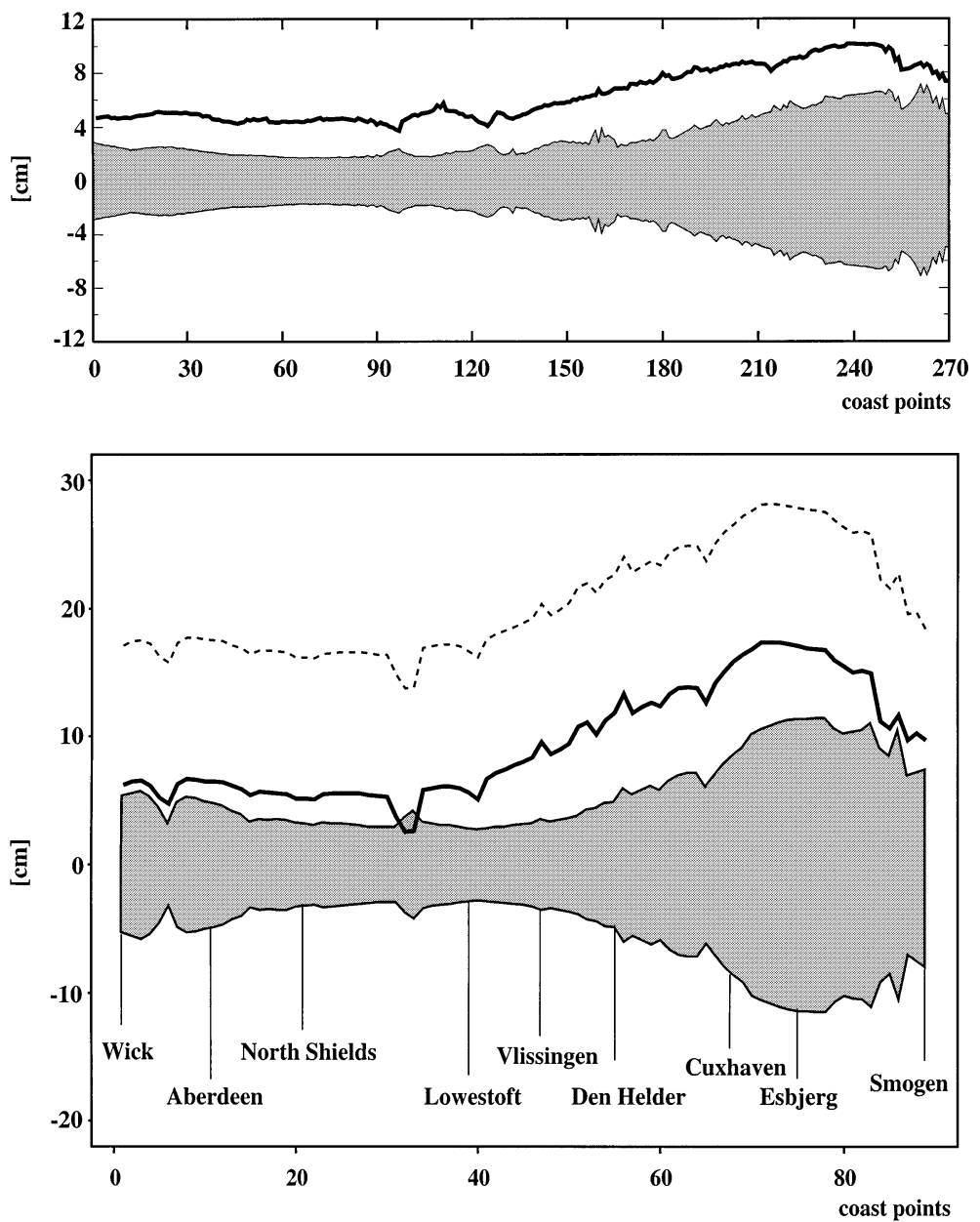

Fig. 2. Difference of the 5 -winter mean of high water levels in the ' $2 \times \mathrm{CO}_{2}$ ' and the control run (_) in (a) HAM SOM and (b) OPYC along the North Sea coast ( 270 and 89 grid points, respectively). The shaded band shows 2 SD of 5-winter mean high water levels, as derived from the hindcast 1955 to 1993 for (a) and 1973 to 1993 for (b). In (b), the difference of the 5-winter mean with thermal expansion taken into account is depicted (----). Vertical lines indicate tide gauge positions (for both top and bottom panel). The scale of the $y$-axis is equal in both panels

Although the OPYC was run only for $15 \mathrm{yr}$ whereas HAM SOM was integrated over $39 \mathrm{yr}$, a higher-and more realistic - variability of sea levels was obtained by OPYC than in the uncorrected HAMSOM. This result has consequences for the length of time series needed. For an assessment of sea level variability on the time scales that are addressed in this paper, it seems to be sufficient to look at $15 \mathrm{yr}$ of data. While the trends that are found in a time series are very sensitive to its length (cf. Langenberg et al. 1999), this does apparently not apply to variability.

Finally, the thermal expansion experiment produced an increase of the mean sea levels by about the same amount that had been added to the sea levels at the open boundaries, while the differences between mean and intra-monthly $90 \%$ quantiles remained virtually 

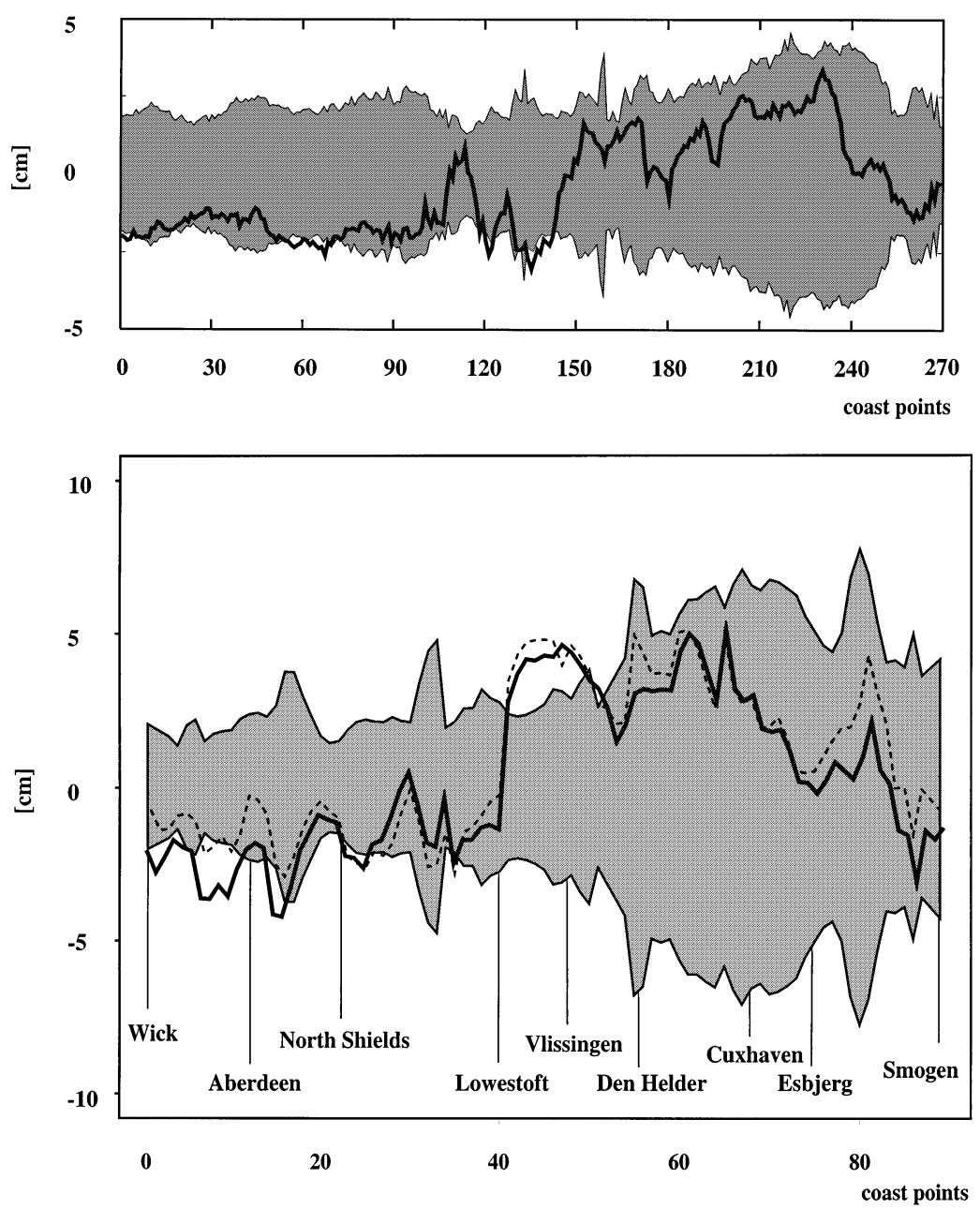

Fig. 3. Difference of the intra-monthly $90 \%$ percentile of high water levels in the ' $2 \times \mathrm{CO}_{2}$ ' and the control run (-) in (a) HAMSOM and (b) OPYC along the N orth Sea coast. The shaded band shows 2 SD of the intra-monthly $90 \%$ quantiles of high water levels, as derived from the hindcast 1955 to 1993 in (a) and 1979 to 1993 in (b). In (b), the difference of the intra-monthly 90\% quantiles with thermal expansion taken into account is depicted (----). Vertical lines indicate tide gauge positions. The scale of the $y$-axis is equal in both panels
Acknowledgements. The authors are grateful to $\mathrm{H}$ ans von Storch and J osef Oberhuber for stimulating discussions. Lennart Bengtsson, Max-Planck-Institut Hamburg, provided the ECHAM3/T106 scenarios and Matthias Dorn and Andre Hufschmidt helped with the data. The work presented in this paper was funded by the Commission of the European Communities within the project 'Climate Change and Sea Level' (contract ENV4-CT95-0124) and by the German Ministry for Education, Science, Research and Technology (BMBF) under contract number 03F0141B. The authors contributed equally to this work.

\section{LITERATURE CITED}

Backhaus J O (1985) A three-dimensional model for the simulation of shelf sea dynamics. Dtsch Hydrogr Z 38:165-187

Beersma J, Rider K, Komen GJ, Kass E, Kharin V (1997) An analysis of extratropical storms in the North Atlantic region as simulated in a control and ' $2 \times$ $\mathrm{CO}_{2}$ ' time-slice experiment with a high resolution atmospheric model. Tellus 49A:347-361

Bengtsson L, Botzet M , Esch M (1995) Hurricane-type vortices in a general circulation model. Tellus 47A:175-196

Cubasch U, Hegerl GC, Hellbach A, Hoeck $H$, Mikolajewicz U, Santer DB, Voss R (1995) A climate change simulation starting from 1935. Clim Dyn 11:71-84

Damm P (1989) Klimatologischer Atlas des Salzgehaltes, der Temperatur und der Dichte in der Nordsee, 1968-1985. Institut für Meereskunde der Universität Hamburg, Tech Rep, 6-89, p 1-81

Flather RA, Smith J (1998) First estimates of changes in extreme storm surge elevations due to doubling of $\mathrm{CO}_{2}$. Global Atmos Ocean Syst 6:193-208

Gibson J K, Kallberg P, Uppala S, Nomura A, Serrano E, Hernandez A (1997) ERA description. ECMWF reanalysis project report 1: Project organisation. Tech Rep

the same. From this it can be concluded that non-linear interactions between thermal expansion and extreme water levels are negligible (at least for thermal expansion induced sea level changes on the order of a few decimeters). From a modelling point of view, this means that both effects can be simulated separatelythe first with a general circulation model, the latter with a regional model - and then added up.

In conclusion, sea level appears to be a rather robust parameter that can be accurately assessed with relatively simple means, as for instance a 2-D barotropic model with external tides. Provided that the underlying atmospheric GCM results resemble the possible future development, we can hope to give fairly reliable estimates of sea levels under changing climatic conditions. viii, European Centre of M edium-range Weather Forecast, Reading

Günther H, Rosenthal W, Stawarz M, Carretero J C, Gomez M Lozano I, Serrano O, Reistad M (1998) The wave climate of the Northeast Atlantic over the period 1955-1994: the WASA wave hindcast. Global Atmos Ocean Syst 6: 121-163

Kauker F (1998) Regionalization of climate model results for the North Sea. PhD thesis, University of Hamburg

Kauker F, Oberhuber J M (1997) An isopycnal ocean circulation model of the North Sea for dynamical downscaling. Tech Rep 97/E/47, GKSS Research Centre, Geesthacht

Langenberg H (1998) Features of coastal current instabilities in the North Sea: results of a numerical model. J Geophys Res C Oceans 103(C4):7681-7691

Langenberg $\mathrm{H}$, Pfizenmayer $\mathrm{A}$, von Storch $\mathrm{H}$, Sündermann J (1999) Storm related sea level variations along the N orth Sea coast: natural variability and anthropogenic change. 
Cont Shelf Res 19:821-842

Luthardt H, Hasse L (1983) The relationship between pressure field and surface wind in the German bight at high wind speeds. In: Sündermann J, Lenz W (eds) North sea dynamics. Springer-Verlag, Heidelberg, p 340-348

Machenhauer $B$, Windelband $M$, Botzet $M$, Hesselbjerg Christensen J, Déqué $M$, J ones RG, Ruti PM, Visconti $G$ (1999) Validation and analysis of regional present-day climate and climate change simulations over Europe. Report 275, M ax-Planck-Institut für M eteorologie, Hamburg

Editorial responsibility: Hans von Storch, Geesthacht, Germany
Oberhuber J M (1993) Simulation of the Atlantic circulation with a coupled sea ice-mixed layer-isopycnal General Circulation Model. Part I: Model description. J Phys Oceanogr 23(5):808-829

Smith SD, Banke E (1975) Variation of the sea surface drag coefficient with wind speed. Q J R Meteorol Soc 101: 665-673

Tomczak G, Goedecke E (1962) Monatskarten der Temperatur der N ordsee, dargestellt für verschiedene Tiefenhorizonte. Dtsch Hydrogr Z Erg-H (B) Nr. 7

Submitted: J une 7, 1999; Accepted: J anuary 2, 2000 Proofs received from author(s): M arch 30, 2000 